\title{
CHALMERS
}

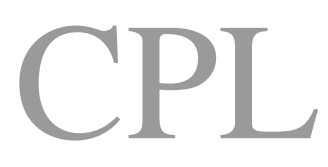

Chalmers Publication Library

Institutional Repository of

Chalmers University of Technology

http://publications.lib.chalmers.se

This is an author produced version of a paper published in Serials Review.

This paper has been peer-reviewed but does not include the final publisher proofcorrections or journal pagination.

Citation for the published paper:

Jonas Gilbert and Jessica Lindholm, "Editorial: Establishing an Open Access Culture among Researchers: Experiences and Challenges at Two Academic Organizations in Sweden" 2011, vol 37, issue 2: pp 67-69

URL: http://dx.doi.org/10.1016/j.serrev.2011.03.014

Access to the published version may require subscription.

Published with permission from: Elsevier 
Establishing an Open Access Culture among Researchers: Experiences and Challenges at Two Academic Organizations in Sweden

\author{
Jonas Gilbert ${ }^{\underline{a}}$ and Jessica Lindholm $\underline{\underline{b}}$ \\ ${ }^{a}$ Gilbert is Head of Publishing Services and Bibliometrics, Chalmers University of Technology, \\ Göteborg, Sweden \\ ${ }^{\mathrm{b}}$ Lindholm is Digital Information Services Librarian, Malmö University, Malmö, Sweden
}

\title{
Open Access Terminology
}

When writing a paper on or discussing open access (OA), one is often made aware that open access terminology is ambiguous and means different things to different people. In this paper we are representing an academic library perspective as advocates of open access at two Swedish academic library institutions. We work mainly with open access to research from institutional repositories, covering the intellectual output of our respective institutions. However, open access can also relate to open access journal publishers, subject-based repositories for research, open books, open educational resources and open data, etc.

Several overviews to open access have been published, such as Keith G Jeffery's introduction to open access in Ercim News (Jeffery, 2006). Another straightforward guide to open access was published by Peter Suber as a field guide to the most common misconceptions surrounding open access. In summary, misunderstandings are related to an assumption of a lesser degree of peer-review in OA publications, traditional (non-OA) publishing being for free, OA not allowing the researcher to choose an appropriate publishing channel and OA killing subscription journals, OA violating copyright, and OA taking too much time. As Peter Suber explains, the answer to the statements above are all "no" (Suber, 2009).

As repository managers, we recognize all of these questions. On the other hand, the major concept of open access is easy for academic institutions to embrace: increased access to research opens up observations to independent scrutiny, fosters new collaboration, encourages further discoveries and increase citations/impact. Why then is open access hard to support in practice, although perceived as easy in theory? In the next sections we will describe the research environment for open access in Sweden.

\section{Research in Sweden}

In 2009 Sweden allocated 3.6 percent of GDP to research. This allocation has led Sweden to be the top-ranking country in the EU in that respect (Swedish Institute, 2010). Sweden produces the largest amount of scientific reports in proportion to its population per one million inhabitants. Swedish research produced 1,159 articles in 2001, followed by Switzerland with 1,126 articles and Israel with 1,030 articles (SASI Group \& Newman 2006). In some research fields, such as agricultural science, science and engineering, Swedish research is cited 25 to 30 percent above the world average (Karlsson and Wadskog, 2006). Even though open access is global by its nature, we do start with different conditions in practice. Not only does scientific production and research infrastructure matter, but also open access is another way to describe the national initiatives.

During the years 2004-2006, the Association of Swedish Higher Education, the Swedish Research Council and the National Library of Sweden all signed the single most important reference for institutions promoting open access, the Berlin Declaration on Open Access to Knowledge in the Sciences and Humanities. These organizations have continued to lead in promoting open access in Sweden. For instance, the national program, openaccess.se, supported a vast number of projects regarding development of repositories and awareness-raising on open access. Within the program and operated by the national library, a national search service for research publications, SwePub, ${ }^{1}$ was launched in late 2009.

In 2010 the Swedish research funders also began demanding open access in practice. Research in Sweden is financed and promoted primarily by the Swedish Research Council, and their decision to include an open access mandate for all its research grants from 2010 is crucial (Swedish Research Council, 2010). There are now four mandates from Swedish research funders (Hagerlid, 2011).

A setback happened in 2008 when the Swedish Research Council postponed its open access policy work due to results in a survey of how many of the Swedish Higher Education (HE) institutions provided their researchers with an institutional repository. As described by Ingegerd Rabow, "Unfortunately, this survey was incomplete (only 15 out of 42 HEs had responded), and thus did not present the true picture. As a matter of fact, all Swedish universities, with the exception of the Karolinska Medical University, have repositories” (Rabow, 2009). Besides the fourteen universities, there are twenty-one public university colleges and a number of independent institutions, and almost 
all run an institutional repository today. Until now Swedish HEs had three open access mandates (Hagerlid 2011). Two of these policies will be presented here.

\section{Policies and Incentives at Chalmers University of Technology and Malmö University}

The open access policy at Chalmers University of Technology was adopted in January 2010, and Malmö University adopted its policy in March 2011. The policy at Chalmers is mandating open access copies in the institutional repository as the general rule of making Chalmers research freely available (Kinger, 2010). Malmö University's policy covers open access in the same way, but also consists of a mandate for open access to local publication series (Lindholm and Nilén, 2011 and policy release text $2011^{2}$ ). Both organizations have been working with the preparations of the policies over a long period of time before the actual decisions, which were made by the President/Vice-Chancellor at the two organizations.

\section{Open Access from Institutional Repositories}

At Chalmers the objective of the decision was clearly stated as an ambition to make all published research results freely available to everyone, and the open access policy guarantees that the scientific results of the university will be as widely distributed as possible. The means for achieving this is a demand on the researchers to deposit their journal articles in the institutional repository (Chalmers Publications Library ${ }^{3}$ ). Normally, this should be done within 6 months from the primary publication date, but not later than 12 months. The First Vice President has the possibility to grant exceptions from the policy on the ground of prestige or impact for a publication, and the researchers are asked to address such cases in writing to the First Vice President.

Malmö University's policy is directed to authors of all kinds of academic publications: articles, dissertations, conference papers, book chapters, books and reports. The policy excludes unpublished research/preprints, nor does it cover publications where staff are editors. In practice the policy means that every researcher needs to identify his/her rights in relation to depositing a copy in the institutional repository (Malmö University Electronic Publishing, MUEP ${ }^{4}$ ) in every publisher contact taken after March 1, 2011. The policy does not apply retroactively; hence, already published material and publisher contacts taken before that date are excluded. In cases when the publisher says yes to deposit, the researcher must deposit a copy in MUEP directly after the publication has been published, but possibly with a delayed open access due to the publisher's stipulated embargoes. If the publisher says no, the policy is still executed. If a researcher, on the other hand, is allowed to deposit a copy and decides not to do so, an opt-out is required from the prefect. This makes it a policy with a loop-hole, as it acts on the publishers' discretion. Malmö accepts all embargoes to be long and even accepts a no to open access from the publisher. Chalmers has a stricter approach, which minimizes the loop-hole and accepts delayed access up to 12 months but allows opt-outs to be asked for.

Another challenge in Malmö's policy is the fact that the policy prescribes that all types of published research, not only articles, must be open access, that is, also monographs and chapters, etc. The lack of a tool for author rights for this material makes it important to stress the benefits of SPARC's Author Addendum,, 5 for example, as well as supporting researchers with general letters of intent to publishers and cover letters in relation to publishing of books and chapters.

\section{Open Access Journals}

Both university policies include a recommendation for the researchers to publish in open access journals (gold open access). Chalmers has backed this up with a recommendation not to transfer copyright, whereas both institutions will be using these new incentives to promote the benefits of open access to the researchers. The policy is also intended to provide an opportunity to highlight the benefits of open access in terms of greater impact, more citations and greater visibility by forcing the researcher to think about his or her rights.

\section{Success in Implementation}

From reactions and questions from the researchers, we have been able to see a lack of understanding about open access or how it can be of benefit to the researchers themselves. There are also misunderstandings regarding the policies. The teams working with support have been asked questions such as: “Am I not allowed to publish in traditional journals?”and “Won’t open access eliminate peerreview?” The need for clear and correct information about open access in general, as well as for the university policies, is then obviously considerable.

How successful have the implementations been so far? What deposit rates have been achieved? Of course, it is still too early to do any definite calculation even for the first year, and a more thorough follow-up will be made. According to SwePub, of the 1,249 scientific peer-review articles published by researchers at Chalmers in 2010, 7.8 percent is available free online. Even though these numbers taken at face value cannot in anyway be called satisfying, they still clearly indicate the beginning of the process. We can see this if we compare the rate of free online articles for the year before the mandate 
and also add the rate for another technical university in Sweden without a mandate, the Royal Institute of Technology in Stockholm.

Malmö University has been working on creating open access to publications produced by its researchers for several years, and already in 2003 a recommendation was made by the vice-chancellor to support open access publishing. In relation to Chalmers, Malmö produces a small amount of research, c:a 200 peer-reviewed research articles a year (the total research output per year is c:a 650700 publications). Malmö offers 19 percent (36/189) of the peer-reviewed scientific articles as open access for 2010. A comparable organization in relation to having a similar open access policy as Malmö over the last four years is Blekinge Institute of Technology is also shown in Table 1.

Table 1. Percentage of peer reviewed scientific articles available free online, publishing year ${ }^{a}$

2009 (percent) 2010 (percent)

\begin{tabular}{lll}
\hline Chalmers University of Technology1.6 & 7.8 \\
Royal Institute of Technology & 0.9 & 1.8 \\
Malmö University & 19.5 & 19 \\
Blekinge Institute of Technology & 13.8 & 27.8 \\
\hline
\end{tabular}

a Scientific peer reviewed articles. Percent available free online. (http://swepub.kb.se/ 2011-03-21).

In an analysis of the process for open access at Queensland University of Technology - which is an internationally recognized successful open access model - Armbruster (2010) lists the following factors as important for success: (1) regular policy review, (2) well-funded implementation, (3) improved repository service, and (4) demonstration of benefits to authors. From our experience we recognize these factors as important.

During Chalmer's first year with the policy in place, a few revisions have already taken place by having a new organization in place, as well as revising the policy as regards which publication types the policy applies to.

Malmö University has already seen a few changes that could be made to the policy, for instance, by having a mandatory upload to a closed access area (for the cases when the publisher says no to open access). This change is to allow for end users to request a copy by an email function, for example. As pointed out by Sale et al., we may need the publisher's permission to make research open access, but we do not need the publisher's permission to deposit it (Sale et al., 2010). This will ensure the potential readers with the content they need.

Armbruster (2010) summarizes their policy work: "Implementing open access is a tough job.” Implementation is undoubtedly also an instructive task where valuable experiences are made by many stakeholders and enforces both libraries' and the research community's core activities. Open access truly allows research to be used and reused, and, highly important, open access moves knowledge forward.

\section{References}

1. http://swepub.kb.se.

2. Malmö University Open Access Policy, http://www.mah.se/english/Library/Electronic-

Publishing/Research-publications/Open-access-policy-at-Malmo-University/.

3. http://publications.lib.chalmers.se/.

4. http://www.mah.se/muep.

5. SPARC Author Addendum. http://www.arl.org/sparc/author/addendum.shtml.

\section{References}

- Armbruster, C. (2010). “Implementing Open Access: Policy Case Studies.” Retrieved from http://ssrn.com/abstract=1685855.

- Hagerlid, J. (2011). “Open access i Sverige - lägesbeskrivning 2011.” Retrieved from http://www.kb.se/dokument/Om/projekt/open_access/2011/OA_Sverige_l\%C3\%A4gesbeskrivning201 10118.pdf.

- Jeffery, Keith G. (2006). “Open Access: An Introduction,” ERCIM NEWS, No. 64 (January 2006): 1617, Retrieved from http://www.ercim.eu/publication/Ercim_News/enw64/EN64.pdf.

- Karlsson, S., \& Wadskog, D. (2006). "Hur mycket citeras svenska publikationer? Bibliometrisk översikt över Sveriges vetenskapliga publicering mellan 1982 och 2004 - Vetenskapsrådet.” Retrieved from

http://www.vr.se/huvudmeny/trycktochpublicerat/analysochuppfoljning/hurmycketciterassvenskapubli kationerbibiolmetriskoversiktoversverigesvetenskapligapubliceringmellan1982och2004.4.2197dce310 eccdec28d8000340.html.

- Kinger M., (2010). “Chalmers Choosing the Green Path to Open Access,” sciecominfo, v. 6, no. 1. Retrieved from http://www.sciecom.org/ojs/index.php/sciecominfo/article/view/3552/3126. 
- Lindholm, Jessica \& Nilén, Peter (2011). “A new open access policy for Malmö University,” sciecominfo, v. 7, no. 1 . Retrieved from

http://nile.lub.lu.se/ojs/index.php/sciecominfo/article/view/4910.

- Rabow, Ingegerd. (2009). “The Swedish Research Council and Open Access,” sciecominfo, v. 5, no 1. Retrieved from http://www.sciecom.org/ojs/index.php/sciecominfo/article/viewFile/1512/1250.

- Sale, A., Couture, M., Rodrigues, E., Carr, L. and Harnad, S. (2010) "Open Access Mandates and the 'Fair Dealing' Button,” In: Dynamic Fair Dealing: Creating Canadian Culture Online (Rosemary J. Coombe \& Darren Wershler, Eds.). Retrieved from http://eprints.ecs.soton.ac.uk/18511/.

- $\quad$ SASI Group \& Newman, M. (2006), Worldmapper.org Science Research, Retrieved March 22, 2011 from http://www.worldmapper.org/display.php?selected=205.

- Suber, Peter. (2009) “A field guide to misunderstandings about open access,” SPARC Open Access Newsletter, issue \#132, April 2, 2009. Retrieved from http://www.earlham.edu/ peters/fos/newsletter/04-02-09.htm\#fieldguide.

- Swedish Institute (2010). “Facts about Sweden : Higher Education and Research,” Updated December 2010. Retrieved from http://www.sweden.se/eng/Home/Education/Research/Facts/Higher-educationand-research-in-Sweden/.

- Swedish Research Council (2010). Decision on open access. Retrieved from http://www.vr.se/inenglish/aboutus/policies/openaccess.4.44482f6612355bb5ee780003075.html. 